\title{
LA COMPETENCIA LECTO-CRÍTICA EN ENTORNOS DIGITALES: UNA VISIÓN HOLÍSTICA PARA L2/LE
}

\author{
Natasha Leal Rivas \\ Università degli Studi di Napoli Federico II (Italia)
}

\begin{abstract}
RESUMEN: Los nuevos procesos de lectura y escritura deben fomentar la construcción de un pensamiento crítico en línea con las necesidades de aprendizaje social que el siglo XXI demanda. La Universidad debe asumir el reto de mejorar la competencia lectoescritora con nuevos y significativos procesos de alfabetización, integrando enfoques cognitivos, constructivistas y conectivos para un aprendizaje competencial transferible a contextos de uso académico y profesional reales.
\end{abstract}

Este estudio reflexiona cómo posibilitar un proceso de aprendizaje lingüístico consciente a través de la competencia crítica aplicada a la recepción y producción de textos discursivos. El marco teórico engloba de forma interdisciplinar enfoques de la Didáctica de la Lengua y la Literatura (DDL) y LIJ, la Lingüística Aplicada a una lengua meta (LM), el Análisis del Discurso, la Pragmática intercultural y las Nuevas Literacidades digitales.

Al estudio se une una propuesta experimentada en el currículo universitario, en concreto de Español Lengua Extranjera (ELE), que propone la secuencialización de estrategias cognitivas posibilitadoras de la reflexión consciente de la lengua y el análisis de textos con muestras reales, que permiten desarrollar prácticas discursivas reales y eficaces dentro de un modelo de Competencia Comunicativa Intercultural Crítica.

PALABRAS CLAVE: literacidad digital, Lingüística Aplicada, aprendizaje cognitivo-discursivo, LM, LIJ.

\section{CRITICAL READING COMPETENCE IN DIGITAL ENVIRONMENTS: A HOLISTIC VISION FOR L2 / LE}

ABSTRACT: The new reading and writing processes should encourage the construction of a critical thinking in line with the needs of social learning that the 21 st century demands. The University must take up the challenge of 
improving literacy competence with new and significant literacy processes, integrating cognitive, constructivist and connective approaches for a transferable competency learning to contexts of real academic and professional use.

This study reflects how to enable a process of conscious linguistic learning through critical competence applied to the reception and production of discursive texts. The theoretical framework includes interdisciplinary approaches to the Didactics of Language and Literature (DDL) and LIJ, Applied Linguistics to Target Language, Discourse Analysis, Intercultural Pragmatics and New Digital Literacies.

The study joins a proposal experienced in the university curriculum, specifically Spanish Foreign Language (ELE), which proposes the sequencing of cognitive strategies that enable conscious reflection of the language and the analysis of texts with real samples, which allow to develop practices real and effective discourse within a model of Critical Intercultural Communicative Competence.

KEYWORDS: Digital Literacy, Applied Linguistics, cognitive discursive learning, target language, LIJ.

Recibido: 15/05/2019

Aceptado: 05/09/2019

Correspondencia: Natasha Leal Rivas, Università degli Studi di Napoli Federico II. Email: lealrivas@unina.it.

\section{INTRODUCCIÓN}

Las nuevas formas de lecturas y escrituras que emergen en el siglo XXI han cambiado radicalmente los paradigmas científicos relacionados con estos procesos y han abierto una revolución sin precedentes en el ámbito educativo. Los numerosos estudios críticos desde la multiplicidad de enfoques y disciplinas prueban a dar respuestas a través de nuevas literacidades y de modelos de aprendizaje cognitivo, constructivista y conectivo. La inabarcable producción crítica interdisciplinar permite ampliar múltiples dimensiones teóricas, metodológicas y científicas hacia nuevos paradigmas híbridos que puedan "recontextualizar" (Martos y Campos, 2012) los nuevos alfabetismos de lectura/escritura que los nuevos espacios y soportes de la era digital proporcionan. De implicación directa con dichos procesos, cabe "recontextualizar" igualmente, métodos y enfoques teóricos que sustentan la enseñanza/aprendizaje de lenguas desde una dimensión cada vez más competencial y contextualizada en un entorno social y cultural digital.

Para este entramado y complejo panorama de alfabetización del siglo XXI, el enfoque interdisciplinar parece ser la perspectiva adecuada para establecer el diálogo entre saberes, un diálogo híbrido y poliédrico que constituye la base del proceso cultural actual. Sin negar la dificultad intrínseca que conlleva el diálogo interdisciplinar, probablemente debido al control que subyace dentro de los propios ámbitos discipli- 
nares más que a un impedimento real que supone el pasar de un registro científico a otro, no obstante, y para comprender los fenómenos de nuestra contemporaneidad, es necesario abrirse a él para una mejor visión holística del propio ámbito científico. Un ejemplo paradigmático son los nuevos fenómenos de lectura y escritura del siglo XXI. Resulta particularmente interesante la visión de Martos y Campos (2012: 5) que proponen estudiarlos como procesos holísticos de comprensión de la realidad al fin de proporcionar un espacio de reflexión teórica al "cruce de códigos" y a la (trans) literacidad "integradora" que muestran las posibilidades interdiscursivas actuales. Sostienen que los nuevos alfabetismos y las nuevas manifestaciones han ampliado nuestra comprensión de la realidad gracias a los procesos dinámicos y de cruces entre códigos y lenguajes (transficcionalidad, intermedialidad, intertexto...) y definen la transliteracidad como la capacidad de leer, escribir e interactuar a través de una gama de plataformas, herramientas y medios de comunicación que va desde la oralidad hasta las redes sociales digitales. Las nuevas literacidades y multimodalidades demuestran, por tanto, una nueva forma de cómo se lee el mundo, la palabra (y los signos) en los múltiples lenguajes contemporáneos y, en este sentido, Cassany (2017: 7) puntualiza además que "la investigación sobre la literacidad debe incorporar una perspectiva sociocultural, a la lingüística y a la cognitiva. Esta perspectiva debe adoptar un punto de vista más global, interesándose por los interlocutores, sus culturas, sus organizaciones sociales, las instituciones con las que se vinculan, etc."

La Red permite desde luego una "convergencia de lenguajes" y nuevos múltiples códigos (multi-alfabetización) que inciden en el ámbito académico y profesional y, por tanto, en la construcción de un discurso social (Martos y Campos, 2012: 6). Al respecto, los autores Ilaman al compromiso de todas las instancias educativas como mediadores para (re)formular todos los espacios y soportes de lectura y escritura para activar procesos de alfabetización funcional y favorecer una apropiación de los textos orales y escritos que promuevan una construcción de la ciudadanía participativa y transformadora. Desde los postulados de la Educación Social, (Diccionario de nuevas formas de lectura y escritura, Martos y Campos, 2013) se destaca planificar, programar e implementar una intervención educativa acorde a las necesidades de la realidad social contemporánea. Y en sinergía, el ámbito de la Innovación Didáctica y Pedagógica propone también educar e impulsar la construcción social desde un enfoque de competencias transferibles a contextos de uso reales desarrolladas a través de procesos de aprendizaje activos y reflexivos. La competencia lectora y escritora se sitúan de forma natural en el eje central de las competencias básicas, como procesos de aprendizaje significativo en la construcción discursos sociales integradores y transformadores. Junto a otras, la competencia digital ha asumido ya un papel destacado en este proceso de construcción educativa crítica. La educación en valores, el desarrollo de competencias lectoescritoras y la construcción social a través de la adquisición de destrezas digitales parece que sean nociones identificativas de las esferas de la Educación Primaria y Secundaria. Sin embargo, estos principios y modelos de valor deben seguir promoviéndose en la Educación Superior y, por supuesto, desde la formación lingüística. La Universidad debe seguir siendo transmisora de determinados valores existentes o generadora de cambios que permitan la transformación de éstos en otros más acordes con las necesidades académicas y profesionales de la sociedad futura (Leal Rivas, 2019: 77). 
No cabe duda que leer y escribir resulta hoy mucho más complejo en todas las esferas educativas y consciente de ello la Unesco publicó en 2011 un importante recurso pedagógico, Alfabetización Mediática e Informacional (AMI): curriculum para profesores. Este documento presenta de forma holística un marco de competencias sistemático y una serie de propuestas de modelos básicos para integrar la AMI en el sistema educativo y propone a los profesores como principales agentes del cambio educativo y de alfabetización. Sin embargo, algunos recientes estudios revelan los esfuerzos que todavía hay que desarrollar para alcanzar una AMI satisfactoria. A modo ilustrativo, un estudio de la Universidad de Stanford (EEUU), realizado en 2016 y dirigido por el profesor de Educación Sam Wineburg, con cuestionarios a casi 8.000 alumnos de educación secundaria y universitaria reveló un insatisfactorio nivel mínimo de razonamiento cívico (una mezcla de capacidad crítica y conocimiento de internet), mostrando un nivel muy bajo de discernimiento (El País, 11/05/2018). Más reciente, en Italia, y con los resultados de las pruebas INVALSI 2019 (Pruebas Nacionales de evaluación del alumnado de Primaria y ESO), según el ISTAT (Instituto Nacional de Estadística del gobierno italiano) más de un tercio de los estudiantes que terminan el ciclo de tres años de la Secundaria de Primer Grado ( $2^{\text {a }}$ ESO) no alcanzan una competencia de alfabetización suficiente (Reppublica, 03/05/2019; Il Corriere della Sera, 03/05/2019). Sin duda, los ejemplos presentados son meramente indicativos pero apuntan hacia una realidad preocupante desde hace tiempo en el ámbito de la Educación y en el área de la DLL: es urgente "recontextualizar" la lectura y la escritura no sólo como destrezas comunicativas sino como procesos conscientes para favorecer la capacidad de discernir dentro y fuera del aula. Si no encontramos alternativas eficaces a la base del proceso educativo, nos arriesgamos en la Educación Superior a no poder afrontar con eficacia problemáticas de alfabetización arraigadas. Al hilo de lo dicho, el Espacio Europeo de Educación Superior (EEES) refuerza también la importancia de tener en cuenta las Nuevas Literacidades Digitales dentro de un nuevo paradigma educativo universitario social, plurilingüe e intercultural. El Marco Común Europeo de Referencia para las Lenguas (Consejo de Europa, 2002: caps 4, 5 y 6) especifica que "aprender lenguas significa adquirir una Cognitive and Academic Proficiency en L2, es decir, poseer una competencia significativa y productiva, que ayude a saber hacer y a interaccionar en un contexto de continuo diálogo intercultural". Es decir, aprender una lengua meta es además aprender a hacerlo con discernimiento.

El presente estudio se enmarca en la formación lingüística universitaria curricular y, concretamente, en la enseñanza/aprendizaje de L2/LE. Las consideraciones que acabamos de presentar buscan dar respuesta a cuestiones como: ¿Cuáles son las formas de lectura y escritura y con qué modalidades podemos proponerlas para desarrollar un aprendizaje lingüístico eficaz y competente que cubra las necesidades académicas de un estudiante universitario y aumente sus posibilidades de desarrollo profesional? ¿Qué rol han de desempeñar los entornos digitales y las TIC para la formación lectora y escritora y, por tanto, en el aprendizaje de L2/LE en el marco de la literacidad digital? ¿qué enfoques y metodologías experimentar para integrar un aprendizaje lingüístico significativo y crítico de la lengua en la formación universitaria académica? Cuestiones no novedosas estas que buscamos dar respuesta en un marco de concreción y de experimentación en el aula. 
Ante la necesidad de proponerse retos en la formación superior hacia el desarrollo de "lectores expertos" (Martinez Ezquerro y Martos García 2019: 21), este estudio se articula en las dimensiones del lenguaje que lo conciben como proceso cognitivo, lingüístico y social para contribuir a una "recontextualización" de las nuevas formas de lectura y escritura universitaria con un estudio de experimentación-acción. Para ello utilizamos un enfoque interdisciplinar que aúna varias disciplinas: las aportaciones de la Didáctica de la Lengua y la Literatura y, en concreto, de la LIJ para ahondar en nociones fundamentales como el desarrollo de estrategias lectoescritoras, la competencia lectora crítica, la educación en valores y la figura de mediador activo en el proceso de aprendizaje; así como los estudios de Lingüística Aplicada, la Lingüística del Texto, el Análisis y Géneros del Discurso para activar procesos de comprensión crítica de géneros y textos discursivos y producción consciente de prácticas discursivas en un aprendizaje lingüístico con un modelo de Competencia Comunicativa Intercultural Crítica (Marimón, 2016; Leal Rivas 2018, 2019). El marco de este estudio se completa con las Nuevas Literacidades Digitales para comprender la noción de texto como proceso continuo donde los formatos hipertextuales e hipermodales que desarrollamos en entornos digitales y colaborativos afianzan el aprendizaje significativo en L2/LE.

El propósito de nuestro estudio nace, por tanto, de la inquietud por experimentar nuevas vías que promuevan un aprendizaje lingüístico competencial, funcional dentro de la formación superior para intentar comprender cómo desenvolverse entre los nuevos paradigmas de lectura y escritura que se van conformando. Todavía hoy persiste en el sistema universitario una concepción reproductiva del conocimiento y ello tiene numerosas repercusiones en las formas de leer y escribir, así como en los métodos de estudio. Por ello, el estudio ofrece una propuesta metodológicamente holística para desarrollar la competencia crítica y la competencia discursiva consciente desde un enfoque interdisciplinar y desde la consideración del lenguaje como proceso cognitivo, lingüístico/textual y social/discursivo.

\section{Dimensión Cognitiva y COMPetencia leCtora CRítica: haCia el APRENDIZAJE CONSCIENTE}

En este apartado nos planteamos el lenguaje como los modos para abordar la realidad y la eficacia de adaptar aspectos del aprendizaje de una L1 en un contexto de L2/LE desde la consideración que "enseñar una lengua" significa en L1 enseñar los usos sociales de la lengua nativa en el cual unimos el sistema/norma junto a los contextos de uso (Rutherford, 1987), distanciándonos de la noción de adquisición de una lengua como proceso acumulativo. Ello nos lleva a entender la adquisición de una L1 como un proceso que también se desarrolla y completa en un contexto educativo y/o académico. En una L1, en la fase previa a la escolarización, la lengua se interioriza junto a contextos de socialización desarrollando lo que Cummins (1983) define como competencias básicas de comunicación (BICS Basic Interpersonal Communicative Skills). El proceso de adquisición de una L1 se completa en el ámbito académico donde se favorece la sistematización de la lengua a través de sus varios registros y modalidades discursivas, desarrollando habilidades cognitivas complejas denominadas CALP (Cognitive Academic Language Proficiency). 
De forma análoga, consideramos que la enseñanza/aprendizaje de una lengua meta (LM) pueda/deba propiciar el desarrollo de un proceso cognitivo complejo similar al aprendizaje sistematizado de una L1. Para ello es interesante atender a macroestrategias que desde la disciplina de la Didáctica de la Lengua y la Literatura (DLL) para la Educación Primaria y Secundaria se potencian y que también se proponen en el aprendizaje de L2/LE:

- crear oportunidades de aprendizaje;

- facilitar la interacción negociada;

- minimizar desajustes en la percepción;

- activar la heurística intuitiva;

- fomentar la concienciación lingüística;

- contextualizar el input;

- integrar las destrezas lingüísticas;

- promover la autonomía del aprendiente;

- incrementar la consciencia intercultural;

- asegurar la relevancia social. (Kumaravadivelu, 1994)

Otro aspecto interesante de la DLL es que no escinde la enseñanza de la lengua y la literatura. Muestra de ello son los numerosos estudios y propuestas que interrelacionan ambos campos desde la competencia lectora crítica. Y es que se retroalimentan: la lengua es el código necesario para entender la literatura y la literatura el camino para aprender los múltiples usos de la lengua tanto en su visión diacrónica como sincrónica. Podemos establecer algunas similitudes en el perfil de desarrollo cognitivo lingüístico de un escolar L1 y en el de un aprendiente, por ejemplo de ELE, dentro del marco actual de búsqueda de nuevos paradigmas de Lectura y Escritura y de nuevos contextos educativos. De hecho, y atendiendo a las macroestrategias apenas citadas, la concienciación lingüística tanto en una L1 (desde la DDL) como en cualquier lengua meta debe ser cíclica, holística y orientada al estudiante mediante recursos y estrategias que darán énfasis a la comprensión, a los principios generales para el aprendizaje de la lengua y a la experiencia operativa.

Al hilo de lo dicho, resulta interesante para desarrollar la dimensión cognitiva hacia la competencia lectora crítica las aportaciones que la Literatura Infantil y Juvenil (LIJ) puede ofrecer al aprendizaje/enseñanza de lenguas extranjeras, además de su particular enfoque pedagógico centrado en la construcción social y de valores. Aunque, la LIJ ofrece muchas posibilidades hacia L2/LE, como el enfoque motivacional e interactivo de la lectura, el enfoque didáctico del corpus LIJ para ELE (Rovira, 2016) o su enfoque social de lectura a través de la Red y la LIJ 2.0 (Llorens y Rovira, 2015), lo cierto es que algunas perspectivas resultan interesantes. Una, la figura del profesor como mediador para fomentar la alfabetización funcional entendida esta como un proceso donde la adquisición de la lectoescritura debe corresponderse con una educación lingüística y literaria significativa (Quiles y Campos, 2015: 179-180). Otra fundamental, el desarrollo de una Competencia Lectora Crítica través de la formación del lector literario (Colomer, 
1998) y el desarrollo de una Competencia Lecto-literaria a través de su componente básico: el intertexto lector (Mendoza Fillola, 2001) que regula la actividad de identificación y conexión en el proceso de lectura e interpretación significativa de un texto. El conjunto de saberes, estrategias, recursos lingüísticos y socioculturales presentes en el intertexto lector se activan a través de dos elementos: uno que se encuentra en la "interacción" con el texto y que podemos identificar en palabras de Gray (1960, citado por Cassany, 2017) a través de una lectura "entre líneas" (comprensión inferencial) y de una lectura "tras las líneas" (comprensión ideológica). La noción de acto interactivo es un proceso que se aplica al texto literario como discurso y análisis de la lengua; otro elemento son las correspondencias entre textos diversos que se activa de forma clara en una fase de recepción potenciando la comprensión crítica de un texto.

El intertexto lector en el proceso de aprendizaje de una lengua puede corresponderse con el conjunto de conocimientos, estrategias, saberes, recursos lingüísticos y socioculturales que, a modo de transferencia cognitiva, podrá transferir desde su L1 a la L2/LE a través de la lectura y comprensión crítica del texto hacia un aprendizaje significativo y consciente.

El destacado interés por el desarrollo competencial oral en ELE en los últimos años ha puesto de relieve una cierta reticencia a integrar la literatura en el aprendizaje de ELE en contextos académicos y curriculares. Contrariamente a cuanto sucede en el ámbito de la DLL donde la literatura es uno de los mayores recursos para el aprendizaje consciente y sistematizado de una L1, su falta en las aulas de ELE supone una grave limitación ya que los textos, literarios o no, son un valor incuestionable para ampliar el intertexto lector de un aprendiente de lenguas. Enumeramos algunas posibilidades de la LIJ que mejorarían el aprendizaje lingüístico para L2/LE y que se recuperan de forma interpretativa. (Cassany, 2002: 502)

\begin{tabular}{|c|c|}
\hline LIJ & L2/LE \\
\hline Competencia Lecto-literaria & Competencia de Comprensión Crítica \\
\hline $\begin{array}{l}\text { Desarrollar hábito lector } \\
\text { (placer por la lectura) } \\
\text { Formación de un lector crítico }\end{array}$ & $\begin{array}{l}\text { Utilizar textos y tipologías discursivas cercanas a los } \\
\text { aprendientes (sobre todo en Red). Utilizar un análisis } \\
\text { funcional de la lengua que permita al aprendiente de- } \\
\text { sarrollar una comprensión crítica del proceso de apren- } \\
\text { dizaje lingüístico }\end{array}$ \\
\hline $\begin{array}{l}\text { Toma decisional del alumno en las } \\
\text { lecturas }\end{array}$ & $\begin{array}{l}\text { Utilizar los análisis de necesidades de aprendizaje } \\
\text { lingüístico para conocer tipologías textuales que ne- } \\
\text { cesita aprender }\end{array}$ \\
\hline $\begin{array}{l}\text { Visión global de la Literatura (cine, can- } \\
\text { ción, cómic, culturas de consumo...) }\end{array}$ & $\begin{array}{l}\text { Visión global de la lengua (hipermodalidades e hiper- } \\
\text { textualidades lingüísticas). Literacidad digital }\end{array}$ \\
\hline Promover dinámicas de creación & $\begin{array}{l}\text { Desarrollar prácticas discursivas orales y escritas tam- } \\
\text { bién creativas y no sólo aquellas de contexto de uso per- } \\
\text { sonal o profesional. Versionar, escribir o reescribir textos }\end{array}$ \\
\hline LIJ 2.0 en constante evolución & $\begin{array}{l}\text { Materiales y recursos de explotación para ELE (acceso } \\
\text { a obras, guías de lectura, herramientas de promoción } \\
\text { lectora, actividades de lectoescritura...) }\end{array}$ \\
\hline
\end{tabular}


Cerramos estas reflexiones sobre LIJ/ELE como binomio para desarrollar un aprendizaje consciente de la lengua desde el desarrollo de la competencia lectora crítica y la importancia de vincular la formación lectora de LIJ con la necesidad de formar nuevos lectores críticos en el aprendizaje de L2/LE. Destacamos también las posibilidades de LIJ 2.0 donde podemos encontrar uno de los mayores corpus de obras literarias en español en la Red para infantil y juvenil así como numerosos estudios que conforman el corpus teórico de esta reciente disciplina (Rovira, 2019). Y también la importancia de abrir la LIJ hacia su componente de desarrollo de oralidad (escuchar y contar cuentos). En este sentido, y aplicado a la formación superior, resulta interesante algunas reflexiones sobre recuperar la lectura como una práctica viva y social, "como debate, intercambio o comunicación", proponiendo aplicaciones metodológicas que fomenten la interrelación y retroalimentación lectora (Martínez Ezquerro, 2016) a través de los textos literarios, o en nuestro ámbito de ELE, con el análisis discursivo y las tipologías textuales.

\section{Dimensión lingüística Y COMPETENCIA DISCURSIVA CRÍtiCA: TRANSFERENCIA SIGNIFICATIVA}

El Marco Común Europeo de Referencia sostiene que "no puede haber un acto de comunicación por medio de la lengua sin un texto" (MCER, 2002: 95). De la misma manera, el Plan Curricular del Instituto Cervantes (2007: 321) subraya la necesidad de adoptar un enfoque basado en los géneros discursivos, orientando el aprendizaje de ELE desde una dimensión textual:

El género ofrece una perspectiva holística que permite trabajar todos los recursos de la lengua desde distintos puntos de vista (funcional, nocional, gramatical, pragmático), haciendo hincapié en el aspecto lingüístico que se adecue a la situación de aprendizaje sin perder la perspectiva global de su uso en contexto. El tratamiento de los textos desde el punto de vista del género al que pertenecen facilita que el alumno perciba de forma global, y en sus distintos componentes, la función comunicativa que cumplen en el contexto social para el que fueron creados.

No obstante, el marco conceptual y el abundante corpus de estudios sobre géneros textuales y análisis del discurso aplicado a la enseñanza de L2/LE, compartimos con Marimón (2016: 194) la falta de un modelo sistematizado y sobre qué "tipo de análisis sería posible conectar los contenidos lingüísticos y los interculturales y sociales en un currículum de español L2/LE" desde la concienciación discursiva crítica. Para la práctica de una Competencia Crítica en L2/LE se debe asumir la necesidad de formar hablantes críticos aplicando los conceptos de Comprensión y Literacidad Crítica. Construir un perfil de Lector Crítico supone orientar el proceso de aprendizaje lingüístico en torno al texto y a los géneros del discurso en una dimensión holística, cognitiva y social. Nuestro lector crítico de L2/LE ante los textos de acuerdo con López Ferrero y Martín Peris (2010: 509) "sabe que hay VARIOS significados (dinámicos, situados); dialoga, busca interpretaciones SOCIALES; lee diferente cada GÉNERO; pone énfasis en la IDEOLOGÍA. Busca la intención; presta atención a lo IMPLÍCITO; busca VARIAS fuentes, contrasta; etc."

Para ser capaces de encontrar los modos de abordar la realidad (Werlich, 1975, citado en Calsamiglia y Tusón, 1999) e interpretar el sentido de las representaciones 
del lenguaje en (López García, 2006) es fundamental que el aprendiente de L2/LE se acerque a la lectura y comprensión crítica de los textos desde una concienciación de las tipologías textuales y géneros discursivos cuya clasificación es muy similar prácticamente en todas las lenguas.

No cabe duda, por tanto, del cambio en la forma de acercarse al estudio del lenguaje y a la noción de "texto" en L2/LE desde los postulados de las Nuevas Literacidades y Nuevas alfabetizaciones funcionales que centran el punto en la Comprensión Crítica. En la dimensión lingüística de nuestro estudio consideramos la Lingüística del Texto un enfoque pragmático fundamental ya que afronta los fenómenos textuales (anáfora, elipsis, marcadores textuales, mecanismos de cohesión y coherencia), los cuales cabe implementarlos de forma sistemática en si queremos avanzar hacia la comprensión crítica de los textos.

Desarrollar pues una competencia discursiva consciente, fundada en la comprensión crítica de textos y en la creación /producción consciente e implicada socialmente debe realizarse desde los conocimientos previos (Bisquerra, 2015) que en materia discursiva se posee en otras lenguas a través de un proceso de transferencia significativa discursiva. En la construcción curricular de L2/LE, y siguiendo las necesidades reales discursivas de los aprendientes, se seleccionarán textos reales atendiendo a la tipología textual (Adam 1992) en relación con las varias modalidades de intencionalidad (describir, narrar, argumentar, exponer y dialogar) y a los géneros discursivos (mail, reseña, entrada de blog, carta de protesta, informe, noticia, novela, teatro, biografía, publicidad, etc.). La transferencia significativa discursiva se actualiza gracias a la personalización y adaptación de estrategias cognitivas, de desarrollo progresivo (Zapata Ros, 2005), adecuadas para fomentar una competencia crítica de lectura y escritura a partir de un eficaz análisis discursivo basado en necesidades reales de comunicación. En las posibles actividades que realicemos para fomentar la comprensión textual crítica (inferencial e ideológica) deberemos incluir tareas que evidencian los niveles de organización textual (Van Dijk, 1980) dando cuenta del plano global y plano local (oracional) del texto, es decir, atendiendo al contenido semántico del texto (macroestructura), a su distribución (superestructura) y a su constitución oracional y de coherencia morfosintáctica (microestructura).

Pero la Red, en cuanto soporte hipermedia, está caracterizada por la hipertextualidad y la hipermodalidad y los géneros discursivos así como las tipologías textuales están sujetos a variación. Como señalamos en la introducción el texto digital se (re) propone como un proceso continuo que presenta unos rasgos discursivos característicos, con géneros (a)sincrónicos y una marca de identidad que Cassany (2017) define como "intertextualidad proactiva". Estas características definitorias proponen otros modelos discursivos con rasgos específicos (chat, foro, redes sociales, blogs, foros de discusión...). Aunque el PCIC reconoce estas nuevas modalidades explícitamente en un nivel C1-C2, no podemos obviar que hoy en día cualquier tipo de género de transmisión oral o escrita circula en formato digital, y es oportuno plantearse en todos los niveles de aprendizaje lingüístico modelos de aplicación para desarrollar también una adecuada literacidad digital en relación a todos los géneros de recepción y producción oral y escrita porque "se lee tal vez más que nunca a través de la Red, existe una multiplicidad de variedades y tipologías textuales y la posibilidad de acceso a textos en múltiples lenguas, procedentes de otras culturas e ideologías 
posibilita el enriquecimiento personal de la dimensión intercultural y del aprendizaje plurilingüe". (Cassany, 2017)

Impera la necesidad de aprender a aprender la Red con sus nuevas literacidades con el fin de llevar al aula de L2/LE una Competencia Discursiva Crítica. Enseñar a analizar y evaluar textos y géneros discursivos dentro del proceso de aprendizaje lingüístico, va más allá del mero enfoque comunicativo. Promueve una actuación participativa y de construcción social ya que enseñamos las consignas para interpretar y producir textos respetando sus características léxico-gramaticales y de organización conforme a unas normas sociales y unos rasgos contextuales que condicionan un uso determinado del lenguaje. Si además este modelo se propone en entornos digitales y soportes de redes sociales que utilizados de forma adecuada potencian un aprendizaje significativo crítico y acorde a las necesidades reales de los aprendientes/usuarios de una lengua.

\section{Dimensión Social y COMPETENCia intercultural para prácticas DISCURSIVAS EFICACES}

La importancia de esta dimensión social del lenguaje ya la había declarado Bajtin (1979) cuando estableció que la función de los textos y de los géneros discursivos respondía a las varias esferas o ámbitos sociales. El desarrollo de la Pragmática y otras disciplinas afines que ponen al centro del lenguaje como proceso social su fundamentación ha permitido una multiplicidad de estudios teóricos y propuestas que en el ámbito de L2/LE ha privilegiado un enfoque discursivo e intercultural. El modelo que asentó Byram (1997) para una Competencia Comunicativa Intercultural (CCI) supone el fundamento teórico del Marco Común Europeo de Referencia (2002). En el capítulo 5 , sobre competencias generales y comunicativas definitorias de un aprendiente de L2/ LE se reconoce que todo aprendiente es agente social, intercultural y autónomo. Este debe por tanto ampliar su formación lingüística desde la capacidad de reconocerse en su propia cultura hacia el respeto del "otro" y de la diversidad cultural y hacerlo desde un proceso crítico y reflexivo del proceso comunicativo como hemos ido desarrollando hasta aquí.

La lengua, que según Halliday $(1982,27)$ es "el medio por el que se establecen, se desarrollan y se mantienen las diversas relaciones sociales", nos ofrece un sistema de opciones que se (re)construyen en función de las necesidades del hablante y del contexto social en el que los enunciados se actualizan. La perspectiva sociopragmática en L2/LE permite articular un aprendizaje de lengua a través de la cual entender la realidad que representa en sus varias posibilidades discursivas. En el aula de L2/LE el formador como mediador cataliza de forma decisiva dicha "visión del mundo" en cuanto sujeto social. Su función y competencias lingüísticas son prioritarias en el proceso de "construcción lingüística" del aprendiente; de él depende que la dimensión intercultural no sea limitada a manuales preconcebidos y se proyecte también hacia una construcción social. ¿Cómo encajar esta perspectiva de concienciación crítica en L2/LE? ¿Con qué modelo de lengua y con qué herramientas y recursos? nos cuestionamos junto a Marimón (2016: 194). Creemos que desarrollar y potenciar la cognición en la comprensión del discurso sea una de las claves a tener en cuenta en el aula. A través del discurso construimos, transformamos y reproducimos la cultura, el conocimiento que posee 
una comunidad, a la cual nos identificamos y que se formula como un entramado de representaciones organizadas de manera específica a través de procesos sociales, discursivos y cognitivos. El enfoque discursivo e intercultural en L2/LE da cuenta de las relaciones, de los tipos de vínculos, de las variables del contexto comunicativo de una lengua, permitiendo detectar problemas interaccionales y ofrecer adecuadas estrategias para mejorar las habilidades discursivas, tan necesarias también en el contexto de lenguajes específicos (Leal Rivas, 2018). Desarrollar, por tanto, una Competencia Comunicativa Intercultural Crítica como acertadamente ha enmarcado Marimón (2016) es fundamental para promover un aprendizaje crítico intercultural de la lengua que puede además integrar una construcción social. El modelo de lengua debería adaptarse a las necesidades del aprendiente y al registro de uso que necesitará (fines específicos) si queremos encontrar la clave para contextualizar adecuadamente al aprendiente en un plano donde aprender la lengua (dimensión cognitiva y lingüística) se desarrolle a través de la comprensión crítica de los textos y géneros discursivos con los cuales puede reconocer cómo funciona mediante las normas sociales y de uso (dimensión social e intercultural). La competencia crítica discursiva le permite ser "lector crítico" pero también "escritor crítico" ya que este enfoque favorece prácticas discursivas donde "Muestra su "interpretación" de la realidad de forma razonada; Hace emerger su propia voz, que DIALOGA con la de otros; Construye de forma distinta cada GÉNERO; Pone énfasis en la INTERACCIÓN con el lector. Se centra en la comunicación; Busca construir CONOCIMIENTO; Argumenta y contraargumenta; Considera DISTINTOS puntos de vista, además del propio; Concibe escribir como construirse una identidad". (López Ferrero y Martín Peris, 2010: 509)

En definitiva, desarrollar una CCIC parece sugerir que sea necesario proponer de forma sistemática en el aula de L2/LE una competencia crítica a través de un aprendizaje lingüístico adaptado y personalizado que pueda responder a: "¿con qué textos en español L2/LE han de "vivir" quienes deciden aprender esta lengua?; ¿qué hacen con esos textos: cómo los usan? (López Ferrero y Martín Peris, 2010: 511) Sin duda, el aprendizaje de una lengua actualmente "desde una perspectiva crítica requiere ser planteada a partir del contexto de uso" teniendo en cuenta además los nuevos paradigmas de Alfabetización Funcional y las nuevas formas para desarrollar Lecturas y Escrituras Críticas que permitan constructos sociales e interculturales de valor.

\section{Del discurso literario al Registro coloquial: una propuesta HOLÍSTICA DE APRENDIZAJE LINGÜÍSTICO}

La propuesta sigue el modelo aplicativo del Diseño Instruccional (DI) de Smaldino et al., 2002 (citado por Martí Rodríguez, 2009, 113) que integra los varios enfoques de teorías de aprendizaje cognitivista, constructivista y conectivista que hemos ido postulando en nuestro estudio. Su pertinencia como modelo se justifica en una estructura secuencial dividida en fases: Análisis, Diseño, Desarrollo, Implementación y Evaluación. Este modelo que nace para secuencializar objetos de aprendizaje en línea justifica ulteriormente la implementación de nuestra propuesta para el desarrollo de prácticas discursivas en un entorno digital colaborativo (Google Drive) y el desarrollo de una Competencia Crítica en todas las fases 


\subsection{Análisis de Necesidades y de situación de aprendizaje}

La propuesta nace para cubrir necesidades reales que se reflejan en las aulas universitarias de ELE (perfil filológico) para aprendientes no nativos, que aún en contacto con la realidad lingüística y cultural española su conocimiento del registro conversacional coloquial se identifica con un registro estándar propio de manuales y materiales adaptados utilizados en el currículo escolar y universitario. Estos materiales, sin menospreciarlos, sin duda permiten conocer el funcionamiento y la organización de la estructura conversacional española pero ofrecen muy poca información todavía acerca de los mecanismos y fenómenos conversacionales (Cestero, 2016). El Análisis de Necesidades realizado a priori de la implementación de la propuesta revela el perfil de lengua de los participantes B2-C1 (MCER) con la realización de un test de nivel en español desde la plataforma Ave Virtual de Español (Instituto Cervantes) (https://ave.cervantes.es/ prueba_nivel/default.htm). Otras características de los participantes (28) se han conocido mediante una encuesta etnolingüística (https://forms.gle/vtbiDqf1Patb7RMC9) que ha revelado algunas importantes consideraciones que justifican la propuesta:

- Lectura media anual de libros (entre 15-20 libros) un 79\%; libros en español al año (media de 10 libros) un 52,6.

- Utilización de géneros discursivos en el aula: Sí $(63,2 \%)$ predominio de la novela $(89,5 \%)$, periodos más utilizados (Siglos XVII-XVIII) con finalidad principal la comprensión de argumentos y temas; aclarar léxico.

- Reconocimiento de la modalidad del Registro coloquial (identificada casi exclusivamente en el nivel léxico-semántico: fraseología y marcadores conversacionales).

- Escaso conocimiento del nivel pragmático discursivo de la modalidad conversacional que implica el uso de estrategias de cortesía y turnos de habla.

También se propuso un Pretest y Postest para recoger un corpus de situaciones comunicativas basado en los DCT (Discourse-Completion Task) con el fin de observar y analizar un comportamiento discursivo (acto de habla) a un contexto determinado de comunicación. Los DCT permiten que el aprendiente entre en contacto tanto con su L1 como en la lengua meta; reflexione sobre las variables del acto comunicativo (roles de jerarquía, distancia social, gravedad de la situación comunicativa, etc.); reflexione sobre las formas lingüísticas adecuadas al contexto de enunciación; emite discursos. El corpus recabado de los de los DCT está aún en fase de análisis.

\subsection{Diseño}

Se propone introducir el Registro Coloquial Conversacional de forma sistematizada como contenido curricular universitario de ELE que integre rasgos situacionales y primarios de la conversación, análisis lingüístico del registro coloquial por niveles y sus principales fenómenos (derivación apreciativa, tematización, turnos de habla, solapamientos, énfasis y mitigación, cortesía valorizadora...)

Nuestra propuesta en concreto focaliza un aprendizaje especializado del registro coloquial hacia actos de habla de cierta dificultad de adquisición pragmática-discur- 
siva (petición/rechazo) que implican además un uso de la estrategia de cortesía como otra estrategia de difícil sistematización en los varios niveles de ELE desde un enfoque pragmalingüístico. El enfoque social de la lengua (Halliday, 1982) permite trabajar el texto como práctica social con una función concreta en un determinado contexto cultural y aplicar un análisis hacia los mecanismos de la interacción social propios de la conversacionalidad con la finalidad de comprender y decodificar de forma crítica sus características y constantes desde la tipología textual del diálogo teatral (intencionalidad del contexto de emisión y del emisor, mecanismos de inferencia pragmática, etc.).

Para acercar al aprendiente de ELE a la comprensión crítica de textos coloquiales utilizamos el esquema de Porroche (1997) que propone poder utilizar textos prototípicos, también Briz (1998), en varios niveles de actuación pedagógica con textos escritos y orales. A su esquema hemos integrado un plano Receptivo con muestra real. Ambos planos proponen actividades que activen una comprensión crítica del RC en L2/LE:

- Receptivo (textos prototípicos): proceso de (re)conocimiento de los recursos del registro coloquial. Utilización de textos prototípicamente coloquiales (orales y escritos). En nuestra propuesta se utiliza el texto teatral y su representación audiovisual.

- Receptivo (muestra real): proceso de aprendizaje de los recursos coloquiales de la conversación con muestras orales reales (y transcripción).

- Productivo: Utilizar los mecanismos coloquiales aprendidos en prácticas discursivas (orales y escritas).

El diseño de la propuesta utiliza el género teatral o género dialogado (Adam, 1992) como género discursivo (literatura) puente hacia una mejor adquisición del registro conversacional real (lengua); además se potencia la lectura de textos literarios teatrales para crear contextos idóneos de aprendizaje. Como modelo de lectura activa y participativa se adapta el método de cooperación interpretativa (Martínez Ezquerro, 2016) utilizando la Competencia Lectora como proceso de acto de reflexión e interpretación textual. Los textos dialógicos teatrales revelan en su planificación textual estructuras y constantes prototípicas de la comunicación espontánea y facilitan una visión global de cómo funciona la estructura conversacional y la dimensión pragmático discursivo del registro coloquial.

Siguiendo el Plan Curricular Instituto Cervantes (2006) en la construcción de un aprendizaje significativo se posibilita las capacidades del aprendiente como agente social y agente intercultural y autónomo con un diseño de secuencialización de desarrollo cognitivo progresivo (Zapata Ros, 2005): de los conocimientos previos a la interiorización y actualización discursiva.

Para el desarrollo de prácticas discursivas eficaces se han seguido otras experimentaciones prácticas que utilizan los géneros discursivos para fomentar una CCIC en ELE. (Marimón, 2016; Leal Rivas, 2018, 2019)

\subsection{Desarrollo}

En la siguiente tabla se ilustra la estructura de la propuesta con los descriptores de fases correspondientes al DI, estrategias cognitivas desarrolladas y contenidos principales: 


\begin{tabular}{|c|c|c|}
\hline FASE/TAREA & $\begin{array}{c}\text { ESTRATEGIAS HABILIDADES } \\
\text { COGNITIVAS REFLEXIVAS }\end{array}$ & CONTENIDOS \\
\hline EMPEZAMOS & $\begin{array}{l}\text { RAZONAR E INFERIR } \\
\text { Activar conocimientos previos } \\
\text { Organizar y regular el proceso de } \\
\text { aprendizaje }\end{array}$ & $\begin{array}{l}\text { Objetivos /exposición de conteni- } \\
\text { dos de la propuesta } \\
\text { Registro coloquial (rasgos prima- } \\
\text { rios/situacionales) }\end{array}$ \\
\hline ANALIZAMOS & $\begin{array}{l}\text { COMPRENDER, ORGANIZAR Y } \\
\text { SINTETIZAR } \\
\text { Establecer autónomamente las pro- } \\
\text { pias estrategias de aprendizaje } \\
\text { Actitud resolutiva para superar las } \\
\text { dificultades del proceso de apren- } \\
\text { dizaje de forma cooperativa (Méto- } \\
\text { do de Cooperación Interpretativa) } \\
\text { para una comprensión crítica } \\
\text { Activar transferencia discursiva sig- } \\
\text { nificativa } \\
\text { Comprender de forma crítica el } \\
\text { funcionamiento social de la lengua } \\
\text { conversacional } \\
\text { Sintetizar estrategias de produc- } \\
\text { ción/recepción oral } \\
\text { Análisis contrastivo y enfoque de } \\
\text { variación intercultural }\end{array}$ & $\begin{array}{l}\text { Textos Teatrales Contemporáneos: } \\
\text { Lectura de El Método Gronholm } \\
\text { (Jordi Galceran, 2005) } \\
\text { Proyección audiovisual de frag- } \\
\text { mentos del texto teatral (Produccio- } \\
\text { nes Teatrales Contemporáneas del } \\
\text { Ministerio de Cultura y Deporte) } \\
\text { Film El Método de Marcelo Piñeyro } \\
\text { (2005) } \\
\text { Rasgos y constantes generales de la } \\
\text { conversación coloquial }\end{array}$ \\
\hline $\begin{array}{l}\text { ANALIZAMOS EN } \\
\text { PROFUNDIDAD }\end{array}$ & $\begin{array}{l}\text { COMPRENDER, ORGANIZAR Y } \\
\text { SINTETIZAR } \\
\text { Activar reflexión lingüística más } \\
\text { profunda } \\
\text { Analizar rasgos característicos con- } \\
\text { versación (Nivel fono-fonológico, } \\
\text { morfosintáctico, semántico, prag- } \\
\text { mático discursivo) Variación inter- } \\
\text { cultural e interlingüística }\end{array}$ & $\begin{array}{l}\text { Entonación y actos de habla (peti- } \\
\text { ción/rechazo) } \\
\text { Recursos intensificadores y atenua- } \\
\text { dores; Tematización; Derivación } \\
\text { apreciativa; locuciones sintagmáti- } \\
\text { cas; recursos de cohesión (elipsis, } \\
\text { deixis, proformas...); aspectos para- } \\
\text { lingüísticos }\end{array}$ \\
\hline $\begin{array}{l}\text { REFLEXIONAMOS } \\
\text { LA LENGUA }\end{array}$ & $\begin{array}{l}\text { COMPRENDER, ORGANIZAR Y } \\
\text { SINTETIZAR } \\
\text { Actitud resolutiva para superar las } \\
\text { dificultades del proceso de apren- } \\
\text { dizaje de forma colaborativa } \\
\text { Capacidad para aprender de forma } \\
\text { individual o colaborativa } \\
\text { Analizar y reflexionar MUESTRA } \\
\text { REAL conversación espontánea } \\
\text { Comprender la ESTRUCTURA Y } \\
\text { SENTIDO de la oralidad. Variación } \\
\text { intercultural e interlingüística }\end{array}$ & $\begin{array}{l}\text { Turnos de habla/turnos de apoyo; } \\
\text { turnos predeterminados; solapa- } \\
\text { mientos } \\
\text { Cortesía valorizadora y mitigadora } \\
\text { en variantes diatópicas de la lengua }\end{array}$ \\
\hline
\end{tabular}




\begin{tabular}{|l|l|l|}
\hline \multicolumn{1}{|c|}{ FASE/TAREA } & \multicolumn{1}{|c|}{$\begin{array}{c}\text { ESTRATEGIAS HABILIDADES } \\
\text { COGNITIVAS REFLEXIVAS }\end{array}$} & \multicolumn{1}{c|}{ CONTENIDOS } \\
\hline NOS ACTIVAMOS & $\begin{array}{l}\text { INTERACCIONAR } \\
\text { Activar prácticas discursivas reales, } \\
\text { tanto en fase de Recepción como } \\
\text { Producción } \\
\text { Desarrollar de forma proactiva una } \\
\text { competencia digital (Google Drive) } \\
\text { Sintetizar y desarrollar conoci- } \\
\text { mientos adquiridos }\end{array}$ & $\begin{array}{l}\text { MCER, C1: } \\
\text { Prácticas Orales: conversaciones } \\
\text { cara cara informales situaciones } \\
\text { de la vida personal o académica } \\
\text { contraste de opiniones, negocia- } \\
\text { ciones complejas... Peticiones, re- } \\
\text { chazo ...) GRABAR VIDEOS } \\
\text { Prácticas Escritas: cartas, mails ex- } \\
\text { tensos, chats, mensajes en foros, } \\
\text { blogs....(Google Drive) ESCRITURA } \\
\text { COLABORATIVA }\end{array}$ \\
\hline $\begin{array}{l}\text { NOS } \\
\text { EVALUAMOS }\end{array}$ & $\begin{array}{l}\text { EVALUARSE } \\
\text { Ser consciente del propio proceso } \\
\text { de aprendizaje autónomo y de los } \\
\text { procesos de aprendizaje coopera- } \\
\text { tivo. } \\
\text { Activar estrategias de (auto)evalua- } \\
\text { ción } \\
\text { Desarrollar criticidad }\end{array}$ & $\begin{array}{l}\text { DCT (cuestionarios de situaciones } \\
\text { comunicativas), Soluciones descar- } \\
\text { gables, Corrección por pares y con } \\
\text { el tutor, Autoevaluación, Sugeren- } \\
\text { cias y comentarios en Google Drive }\end{array}$ \\
\hline
\end{tabular}

\subsection{Implementación}

La propuesta se desarrolla en modalidad blended learning utilizando la plataforma digital Google Drive para alojar la propuesta que desarrolla numerosos recursos hipertextuales e hipermediales. Por un lado, el valor del hipertexto permite contextualizar la información a partir de otros enlaces o proponiendo actividades relacionadas con el texto. Por otro, el formato hipermedia también mejora la comprensión del texto digital de la propuesta cuando este se combina con imágenes (fijas o no) o sonido (audios, vídeos, etc.), o también cuando se propone en relación al texto en actividades dentro una propuesta didáctica en línea. (Leal Rivas, 2019: 72)

Todos los materiales se encuentran en abierto para el aprendiente, así como las actividades colaborativas y de evaluación. También las prácticas discursivas orales y escritas se alojan en la plataforma Drive como resultado del trabajo colaborativo y el esfuerzo personal. Las tipologías y géneros siguen el Inventario de géneros discursivos y productos textuales para niveles de C1 del PCIC.

\subsection{Evaluación}

Los DCT han sido productivos ya que han dado la oportunidad de poder activar un proceso de reflexión crítica lingüística para asimilar la variación interlingüística e intercultural en actos donde la actualización de la cortesía determina la elección de estrategias lingüísticas dentro del Registro Coloquial conversacional. 
Tanto los DCT como las prácticas discursivas elaboradas han generado un cuantitativo y cualitativo corpus para posteriores análisis que mejoren la implementación de la propuesta en sucesivas etapas.

Las prácticas discursivas escritas y orales en entorno digital han mejorado la implementación de la producción escrita/oral en el aula de ELE, innovando tanto la práctica docente como el proceso de aprendizaje. Además han contribuido a la autonomía que controla el proceso, planifica y gestiona los recursos a disposición del aprendiente, además de mejorar la motivación y el control afectivo. Pero sobre todo ha activado de forma estratégica todas las competencias generales y específicas en L2/LE.

En definitiva, una visión holística y competencial del aprendizaje lingüístico presupone que no hay contenidos fáciles o difíciles que no puedan ser integrados en los varios niveles. Consideramos, por ejemplo, que el Registro Coloquial Conversacional pueda ser presentado en niveles iniciales de forma sistematizada siempre y cuando se seleccionen las muestras de textos (preferentemente reales pero también prototípicos) y se adapten/personalicen o creen las contenidos, materiales y recursos según el nivel y atendiendo a estrategias cognitivas.

\section{Conclusiones}

En este estudio se ha destacado que las investigaciones sobre Nuevas Literacidades y la búsqueda de paradigmas para las nuevas lecturas y escrituras deben ser igualmente centro de interés de los ámbitos disciplinares de la Lingüística para poder contribuir al paradigma de la literacidad desde una perspectiva sociocultural, lingüística y cognitiva integrada. Es por ello que es necesario seguir contribuyendo con reflexiones, estudios y propuestas prácticas que conformen un paradigma axiológico para la literacidad digital y la comprensión crítica, también desde el ámbito lingüístico, en un contexto cultural y social globalizado y digitalizado.

Las aportaciones de la interdisciplinariedad para desarrollar un aprendizaje de lenguas significativo son fundamentales. Así desde la DDL y la LIJ hemos articulado una dimensión cognitiva del aprendizaje de la lengua vinculando la comprensión crítica al hábito lector, la competencia lecto-literaria y al intertexto lector que se desarrolla en las primeras etapas de escolarización. La transferencia significativa de estrategias cognitivas en materia de competencia lectoescritora en L1 son imprescindibles para recuperarlas y posibilitarlas también en L2/LE hacia una transferencia significativa discursiva para poder desenvolverse el aprendiente en un medio social con formas de expresión y comunicación que el entorno actual y los nuevos soportes y dispositivos tecnológicos nos exigen. Desde la formación universitaria lingüística debemos ser conscientes de la utilidad que supone seguir despertando el deseo por la lectura, en todas sus manifestaciones, ya que permite establecer un eslabón entre el mundo interior y exterior del aprendiente, generando una relación directa entre sus conocimientos del mundo con el texto (intertexto lector) y el conjunto de usos de la lengua.

La lectura de textos y géneros discursivos (literarios o menos) facilita, por tanto, una "transferencia significativa discursiva" hacia el análisis lingüístico, el enfoque 
sistemático y la reflexión consciente de la lengua real (muestras orales). Este puente natural que se genera en una L1 sería conveniente abrirlo también hacia una L2/LE si además de un aprendizaje de la lengua queremos posibilitar una construcción social y en valores desde la literacidad crítica.

\section{REFERENCIAS BIBLIOGRÁFÍCAS}

Adam, J. M. (1992). Les textes: types et prototypes. Récit, description, argumentation, explication et dialogue. París: Nathan.

Bajtín, M. (1979). Estética de la creación verbal. México: Siglo XXI.

Benavides Cáceres, D. R. y Sierra Villamil, G. (2013). Estrategias didácticas para fomentar la lectura crítica desde la perspectiva de la transversalidad. REICE. Revista Iberoamericana sobre Calidad, Eficacia y Cambio en Educación, 11(3), 79-109. Recuperado de http://www.rinace.net/reice/numeros/arts/vol11 num3/art4.htm.

Bisquerra, R., Pérez González, J. C. y García Navarro, E. (2015). La inteligencia emocional en educación. Madrid: Síntesis.

Briz Gómez, A. (1998). El español coloquial en la conversación. Esbozo de pragmagramática. Barcelona: Ariel Lingüística.

Calsamiglia, H. y Tusón, A. (2002). Las cosas del decir. Manual de análisis del discurso. Barcelona: Ariel.

Cassany, D. (2005). Los significados de la comprensión crítica. Lectura y vida, 26(3), 32-45.

Cassany, D. (2006). Tras las líneas: Sobre la lectura contemporánea. Barcelona: Anagrama.

Cassany, D. (2017). Investigaciones y propuestas sobre literacidad actual. Recuperado de http://www2.udec.cl/catedraunesco/05CASSANY.pdf.

Cestero, A. M. (2016). La conversación. Bases teóricas y metodológicas para su investigación y su enseñanza en ELE. Linred: Lingüística en la Red, 14. Recuperado de https://ebuah.uah.es/dspace/handle/10017/30208.

Colomer Martínez, T. (1998). La formación del lector literario: narrativa infantil y juvenil actual. Madrid: Fundación Germán Sánchez Ruipérez.

Cummins, J. (1983). Interdependencia lingüística y desarrollo educativo de los niños bilingües. Infancia y aprendizaje, 21, 37-61. Recuperado de http://coordinadoraendl. org/aletramiuda/outros/recomendacions/recom_15_2.pdf.

Halliday, M. (1982). El lenguaje como semiótica social. Interpretación social del lenguaje y del significado. México: Fondo de Cultura Económica.

Kumaravadivelu, B. (1994). The Postmethod Condition: (E)merging Strategies for Second/Foreign Language Teaching. TESOL Quarterly, 28(1), 27-48. Recuperado de https://cvc.cervantes.es/ensenanza/biblioteca_ele/antologia_didactica/enfoque_ comunicativo/kumaravadivelu01.htm. 
Leal Rivas, N. (2018). Aprendizaje consciente en entornos digitales: estrategias cognitivas para una competencia comunicativa intercultura. En S. Chiapello, C. G. Royo, T. M. Sánchez y N. Balafuy (Eds.), Telecolaboración y corpus para el estudio de lengua y cultura (pp. 169-184). Alicante: Servei de Publicacions de la Universitat d'Alacant. Recuperado de https://scholar.google.es/citations?user=G84xd4A AAAAJ\&hl=es.

Leal Rivas, N. (2019). Construcción social y ELE: reflexión metalingüística, interculturalidad y competencia pragmático discursiva en estudiantes de movilidad. Pedagogía social: revista interuniversitaria, 33, 65-78. http://doi.org/10.7179/ PSRI.

López Ferrero, C. y Martín Peris, E (2010). La competencia crítica en el aula de L2/ LE: textos y contextos. En M. A. Celis y J. R. Heredia (Eds.), XXI Congreso internacional de ASELE. Del texto a la lengua: La aplicación de los textos a la enseñanza-aprendizaje del español L2-LE (pp.507-516). Salamanca: Universidad de Salamanca. Recuperado de https://cvc.cervantes.es/ensenanza/biblioteca_ele/asele/ pdf/21/21_0507.pdf.

Marco Común Europeo de Referencia para las Lenguas (2002). Recuperado de http:// cvc.cervantes.es/OBREF/marco/cvc_mer.pdf.

Marimón Llorca, C. (2009). Estrategias discursivas para comprender: enseñar educación para la ciudadanía a estudiantes no nativos. En A. Vera Luján y I. Martínez Santander (Eds.), XX Congreso Internacional de la ASELE. El español en contextos específicos: Enseñanza e investigación (pp. 697-717). Pamplona: ASELE, Fundación Comillas.

Marimón Llorca, C. (2016). Hacia una dimensión crítica en la enseñanza de español como lengua extranjera: La Competencia Comunicativa Intercultural Crítica (CCIC). Revista española de lingüística aplicada, 29(1), 191-21. http://doi. org/10.1075/resla.29.1.08llo.

Martínez Ezquerro, A. (2016). El método de cooperación interpretativa como estrategia lectora. Álabe, 14. http://doi.org/10.15645/Alabe2016.14.

Martínez Ezquerro, A. y Martos García (2019). La lectura en los actuales contextos de educación social: claves desde la formación literaria. Pedagogía social: revista interuniversitaria, 33, 65-78. http://doi.org/10.7179/PSRI_2019.33.01.

Martínez Rodríguez, A. (2009). El diseño instruccional en la educación a distancia. Un acercamiento a los modelos. Apertura. Revista de Innovación Educativa, 10. Recuperado de http://www.udgvirtual.udg.mx/apertura/index.php/apertura4/article/ view/120.

Martos Núñez, E. y Campos, M. (Coords.) (2013). Diccionario de nuevas formas de lectura y escritura. Madrid: Santillana.

Martos, E. y Campos, M. (2012). La lectura y la escritura en el S. XXI: Cultura letrada y modernidad. Álabe, 5. http://doi.org/10.15645/Alabe.2012.5.13. 
Mendoza Fillola, A. (2001). El intertexto lector, Alicante: Biblioteca Virtual Miguel de Cervantes, 2008. Recuperado de http://www.cervantesvirtual.com/nd/ark:/59851/ bmc988p7.

Pardo Abril, N. G. (2007). Niveles de organización del significado en el discurso. Discurso y Sociedad, 1, 85-115.

Plan curricular del Instituto Cervantes. Recuperado de https://cvc.cervantes.es/ ensenanza/biblioteca_ele/plan_curricular/indice.htm.

Porroche, M. (1997). Análisis de textos coloquiales en la enseñanza del español como lengua extranjera. En VIII Congreso Internacional de ASELE La Enseñanza del Español como Lengua Extranjera: del Pasado al Futuro. Alcalá de Henares. Recuperado de http://cvc.cervantes.es/ensenanza/biblioteca_ele/asele/asele_viii.htm.

Quiles Cabrera, M. C. y Campos Fernández-Fígares, M. M. (2015). Una aproximación empírica al español escrito por escolares inmigrados. Revista Internacional de Estudios Migratorios (RIEM), 5(2), 172-200. Recuperado de https://dialnet.unirioja. es/servlet/articulo?codigo $=5588445$.

Sánchez Lobato, J. y Santos Gargallo, I. (2004). Vademécum para la formación de profesores. Enseñar español como segunda lengua (L2 )/ lengua extranjera (LE), Madrid: SGEL.

Rovira Collado, J. (2010). Literatura infantil y juvenil: de la escuela a Internet y de la red a ELE: lección inaugural. En VII Encuentro Práctico de ELE (Madrid, 2010) (119). Recuperado de http://redined.mecd.gob.es/xmlui/handle/11162/80761.

Rovira Collado, J. (2015). Literatura infantil y juvenil en Internet. De la Cervantes Virtual a la LIJ 2.0. Herramientas y espacios para su estudio y difusión. (Tesis Doctoral. Universidad de Alicante, Alicante). Recuperado de http://rua.ua.es/dspace/ handle/10045/46345.

Rutherford, W.E. (1987). Second Language Grammar: Learning and Teaching. London: Longman.

Van Dijk, T. A. (2002). El análisis crítico del discurso y el pensamiento social. Athenea Digital, 1, 18-14. http://doi.org/10.5565/rev/athenead/v1n1.22.

Zapata Ros, M. (2005). Secuenciación de contenidos y objetos de aprendizaje. RED. Revista de Educación a Distancia. Monográfico, II. Recuperado de http://www. um.es/ead/red/M2/. 